\title{
Relationship between Computer-Mediated Communication and Employee Engagement among Telecommuting Knowledge Workers
}

\author{
Tywanda D. Tate ${ }^{1 *}$, Franklin M. Lartey², Phillip M. Randall ${ }^{3}$ \\ ${ }^{1}$ Prosperity Business Solutions Group, LLC, Mobile, AL, USA \\ ${ }^{2}$ Technology-Planning and Forecasting, Cox Communications, Atlanta, GA, USA \\ ${ }^{3}$ Department of Business, School of Business and Technology, Capella University, Minneapolis, USA \\ Email: *phillip.randall@capella.edu, franklin@lartey.net, tdtate7@gmail.com
}

How to cite this paper: Tate, T.D., Lartey, F.M. and Randall, P.M. (2019) Relationship between Computer-Mediated Communication and Employee Engagement among Telecommuting Knowledge Workers. Journal of Human Resource and Sustainability Studies, 7, 328-347.

https://doi.org/10.4236/jhrss.2019.72021

Received: May 11, 2019

Accepted: June 25, 2019

Published: June 28, 2019

Copyright $\odot 2019$ by author(s) and Scientific Research Publishing Inc. This work is licensed under the Creative Commons Attribution International License (CC BY 4.0).

http://creativecommons.org/licenses/by/4.0/

\begin{abstract}
Virtual teams are increasingly expanding across the workforce facing many challenges to remain competitive. Like traditional "brick-and-mortar" workforces, there may be challenges within virtual teams that affect organizational success such as employee engagement, job satisfaction, commitment, leadership, trust, and knowledge sharing. However, it is uncertain how virtual teams maintain long-term sustainability. This research study brings together two constructs, employee engagement and computer-mediated communication, to examine their importance and relevancy in virtual team's effectiveness (success). Further, social exchange theory (SET) theoretical foundation explained employee motivation and satisfaction behaviors. This research employed a quantitative, non-experimental explanatory research design and used two instruments to investigate the relationship between computer-mediated communication (CMC) competence and employee engagement in telecommuting knowledge workers in the US. To measure dimensions of employee engagement, the researchers used the Utrecht Work Engagement Scale (UWES-9) and the Computer-mediated Communication (CMC) competence model to measure 5 subscales of computer-mediated communication, i.e. expressiveness, attentiveness, efficacy, knowledge, motivation. The target population was a random sample of 134 teleworkers. Demographic information collected included age, gender, education level, and number of years of service. The findings suggest that the most significant predictor of engagement is attentiveness, followed by expressiveness, and then motivation. Thus, leadership can engage in telecommuting knowledge workers to increase and maximize productivity.
\end{abstract}




\section{Keywords}

Teleworking, Telecommuting, Remote Workers, Virtual Teams, Knowledge Workers, Employee Engagement, Computer-Mediated Communication

\section{Introduction}

In recent years, information and communication technologies (ICTs) advancement produced significant modifications in organizations and their business practices [1]. For nearly a decade, the use of technology-mediated communication enables workers to collaborate with colleagues across multiple time zones, accomplish work tasks, and keep in touch with the main offices from anywhere at any time [2] [3]. Such information technology (IT) enabled work to be considered as "telework" (Telework Enhancement ACT of 2010)1. Telework, can be referred to as telecommuting, virtual work or remote work. The term "telework" or "teleworking" refers to a flexible work arrangement in which an employee performs assigned duties and responsibilities of an employment position for an approved location from which the employee would work (Telework Enhancement ACT of 2010) ${ }^{1}$. Based on this ACT, examples of telework include work from home or other site geographically convenient to the residence of the employee using diverse digital media tools and enterprise collaboration systems. For employees to successfully work remotely, they need to have the appropriate experience to work with little or no assistance or supervision; they need to be knowledgeable. This study considers teleworkers as knowledge workers who work remotely. In other words, knowledge teleworkers will simply be referred to as teleworkers.

Viewed as a cost-efficient alternative to the traditional work environment, telework has led government agencies and other organizations to implement policies to allow and encourage telework (Telework Enhancement ACT of $2010)^{1}$. For organizations, telework can reduce operational costs, office space, and provide opportunities for sharing and connecting required human resources, information, knowledge and systems through networks to create values that allow employees to more efficiently use organizational resources [4] [5]. Some scholar practitioners have argued by providing enhanced flexibility in work schedules and facilitating cross-functional collaboration and extensive knowledge sharing across organizational perimeters, telework positively influences employees job satisfaction [6] [7]. In contrast, other scholar practitioners pinpointed various factors such as physical isolation, social isolation, and feeling left out or the lack of sense of organizational belonging [8] [9] that may inhibit teleworkers' satisfaction. These studies commonly signify teleworkers concerns about exclusion from decision making in conjunction with being regarded as less committed to their work group, which in turn, lead them to extensively rely ${ }^{1}$ Telework Enhancement Act of 2010, Pub. L. No. 111-292, 124 STAT. 3165 (2010). 
on information technologies to signal their presence and to reduce their sense of social isolation at the remote workplace to a greater degree when they work in an office [1].

There were previous virtual, teleworker and telecommuting related studies that primarily focused on attitudinal or causal variables associated with computer technology such as job satisfaction, job performance, technostress, leadership behavior and employee engagement, and well-being as the main well-being outcomes of interest [5] [10] [11]. To date, there is no existing empirical evidence that explains research on computer-mediated communication competence and employee engagement among teleworkers in the United States or other countries. Further, there is no empirical evidence that exists on computer-mediated communication competence and employee engagement. To fill these gaps in understanding, this study develops and tests a research model that explains employee engagement and overall computer-mediated communication in knowledge teleworkers based on reciprocation, the Social Exchange Theory (SET).

The following discussion presents the theoretical foundation and the constructs addressed in the research, i.e. Social Exchange Theory, Employee Engagement, and Computer-Mediated Communications. The subsequent discussions are organized and presented to facilitate further understanding of the research, i.e. Methodology (Measures/Instruments, Population and Sample, Research Questions); Data Analysis and Results (Post Hoc Statistical Power Analysis, Confirmatory Factor Analysis, Assumptions of the Multiple Regression, Results); Discussion (General Implications, Organizational Implication, Limitations, Recommendations for Further Research); and Conclusion.

\section{Theoretical Foundation and Constructs}

\subsection{Social Exchange Theory (SET)}

Social Exchange Theory (SET) is one of the most prominent and influential conceptual paradigms for understanding work behavior [12] SETs well-respected evidence-based history supports nearly six decades bridging disciplines such as social psychology [13] [14] [15] and sociology [13]. SET has two diverse paths or forms of exchanges: social and economic [13] [14] [15] [16]. Blau (1964) [13] described social exchange as "the voluntary actions of individuals that are motivated by the returns they are expected to bring and typically do in fact bring from others" (pp. 91-92). Tate (2015) [17] noted, "an important concept of social exchange theory is that a person favorably considers others with the expectation of something in return without specifying the terms of exchange" (p. 44). Blau (1964) [13] explained the social exchange as the definite nature that has no specification at the time of the favor or in advance, and the discretions are given to the one who makes it. Therefore, the social exchange is deep-grounded in permanent exchange and undetermined exchange of favor [18] (Aryee et al., 2002) based on a general obligation to reciprocate.

In contrast, the economic exchange is a binding agreement or clear understanding of a negotiated exchanged tied to financial gain with an employer and 
employee in a workplace setting [19]. Some scholars explained economic exchange as a representation of quid pro quo between the employee and the employer [13] [18] to explain motives for employees to engage in extra-role activity [20]. Despite different ways scholars use SET, they concur that exchange relations are both social and economic to describe "a two-sided, mutually contingent, and mutually rewarding process involving 'transactions' or simply 'exchange"' [21].

SET is a broad theory that scholars apply across many disciplines such as human resources [22] management [23], organizational behavior [24] and psychology [25] (Meyer, 2013). "Thus, the social exchange has emphasized socio-emotional aspects of the employment relationship (i.e. feelings of obligation and trust), while economic exchange has emphasized the financial and more tangible aspects of the exchange relationship" [26]. SET is the most applied theory in recent employee engagement studies [27]. According to Bailey [28], Madden, Alfes, and Fletcher (2017), SET rated second as the most frequently applied theoretical framework for engagement. For example, Andrew and Sofian (2012) [27] concluded the social exchange theory supports the reciprocity concept when businesses provide facets to employees such as pay, autonomy, meaningful work, or training, and in return, the employee reciprocates engagement or through higher levels of engagement. Many recent studies have been consistent with finding the social exchange theory supports employee engagement conceptually [16] [27] [29].

Undoubtedly, further investigations of how exchange orientation influences organizational relationships are of great importance particularly with the increasing advent of technology's growing presence in the workplace. It is well known that there are countless advantages and efficiencies for organizations as the direct result of technology. Advancing technology has created a fast-paced, knowledge-based, ever-evolving milieu. For example, the most common form of information exchange used by knowledge workers occurs through computer-mediated communications, which too often leads to misunderstanding, miscommunication, and misinterpretation as well as employee disengagement [30] [31].

By and large, organizational researchers have focused on the social relationships that develop between employees and their employing organization. This study extends this research in taking a close viewing of the relationship between the organization's knowledge workers' use of computer-media communications and the extent of their engagement as a lens on the evolving social exchange theory. And as previously mentioned, the study addresses the gap in the literature that there is no empirical evidence found on computer-mediated communication competence and employee engagement.

\subsection{Employee Engagement}

Today, the US spends over $\$ 720$ million towards employee engagement improvements [32]. Employee engagement can be a critical component to both the 
business and organizational success [17]. According to [33], "it is important that an organization not only understands how to engage employees but should be perceptive to cultivating the right level of engagement, at the right time and target the right employee group" (p. 59). Several practitioners found employee engagement as a key factor to organizational success [34]. According to [35], organizations are placing emphasis on ways to get employees more engaged. Further, [35] found employee engagement as an employee's favorable perception or understanding regarding the organization mission, goals, and values that is reciprocated by the employer. Moreover, [36] described employee engagement as a multi-faceted concept that builds on positive emotions related to the level of engagement. The premise of this study is the relationship between employee engagement and overall computer-mediated communication among knowledge teleworkers.

Employee engagement advanced as an essential model in "industrial and organizational psychology to describe the mental state underlying high degrees of work motivation" [37] According to [38] "Work engagement can be considered a domain specific psychological state that corresponds with positive affectivity, being a context-free dispositional trait" (p. 14). [39] explained three dimensions of work engagement vigor, dedication, and absorption are defined similarly in the literature describing vigor as highly enthusiastic, determined, and commitment to dedicating time and energy toward work despite the existing workplace conditions or circumstances.

[39] defined dedication as having a feeling of importance, motivation, satisfaction, and purpose. The authors explained dedication as active involvement in one's work that exceeds the way one would usually identify one's self with work. [40] stated that an employee who highly correlates to dedication are the employees who find their work to be thought-provoking, meaningful, inspiring, and they feel a strong connection to their work.

Finally, absorption describes an individual being immersed in one's work by which space and time become irrelevant in that it is difficult to disconnect one's self from work [39]. In some instances, absorption may hinder or prevent more than encourage dedication [41]. For example, "employees who identify strongly with their organization and have high work engagement may also engross themselves strongly in negative aspects of their work as well as positive, and as a consequence, their job satisfaction may be hampered" [41]. Further, [41] pointed out that an employee who is unable to easily detach from their work may experience both a diminished personal life and social interactions, resulting in undermining overall positive mood and emotions and global work satisfaction. Similarly, [35] argued that characteristics of work-life are strongly correlated with employee engagement; consequently, a sense of purpose and involvement must be the strongest driver for employee engagement. For these reasons, telework can be a positive alternative work method for employee engagement in an organization. 


\subsection{Computer-Mediated Communication (CMC)}

The computer-mediated communication competence model is a framework developed specifically to analyze the communications environment, the media type or method of exchange, and the interaction among users [42]. The model posits that technology is more effective and positively accepted when used by a competent individual [42]. Technology has revolutionized the way business is conducted. That is, rather than rely solely on face-to-face communication, employers and their employees alike have a wide variety of technology-mediated resources at their disposal. As we have come to know, previous and reportedly outdated telecommunication systems require encoding, transmitting, and decoding of information, while today's computer-mediated communication embodies the creation and exchange of information [42] [43] [44].

As the result of the major change and growth experienced by computer-mediated communication over the past 20 years, while shape shifting from a highly-specialized and technical usage to a usage that is more personal in nature, computer-mediated communication is a relatively new field of study [45]. Computer-mediated communication allows, enables, and facilitates immediate and real-time access to customers, business associates, vendors, and employees around the world. Computer-mediated communication is described as "a dynamic force, the potential for creativity, the element of unpredictability ... where orderly patterns and random developments provide an engaging focus ..." [45].

Computer-mediated communication has changed the way people interact socially, develop their identities, define their relationships, and build their communities [45] [46]. Competency in computer-mediated communication (CMC) significantly explains the variation in overall teleworker engagement. [47] acknowledged that much of computer-mediated communication research had focused on the effects of technology and media while giving less attention to social dimensions and their associated variables. This study is concerned with how competency in computer mediated communication is related to employee engagement in the workplace, and CMC defined as communication carried out using networked devices.

\section{Methodolgy}

This research employed a quantitative, non-experimental explanatory research design, deploying two questionnaires to determine the relationships between computer-mediated communication (CMC) competence and employee engagement in telecommuting knowledge workers in the US.

\subsection{Measures/Instruments}

\section{Utrecht Work Engagement Scale (UWES-9)}

The Utrecht Work Engagement Scale (UWES-9) developed by [48] was used to measure all dimensions of employee engagement. According to [17], the UWES-9 illustrated internal consistency across over 10 countries ranging be- 
tween 0.85 and 0.92 (p. 100). [48] noted the UWES-9 is usable for positive organizational behavior and contain sufficient psychometric properties (p. 701). The 9-item scale consists of a 7-point Likert-type scale ranging from 0 (never) to 6 (always). This scale is comprised of three dimensions or sub-scales: vigor, dedication, and absorption [48]. Multiple studies defined engagement as a "positive, fulfilling, work-related state of mind that is characterized by vigor, dedication, and absorption" [39] [49].

\section{Computer-Mediated Communications}

The Computer-mediated Communication (CMC) competence developed by [44] measured computer-mediated communication competence. This study focused on 4 of 15 subscales: motivation, knowledge, efficacy, and attentiveness. [50] proved that the reliability (internal consistency) of these subscales measure above 0.70 . The 21-item scale was comprised of a 6-point Likert-type scale ranging from 1 (strongest disagreement) to 6 (strongest agreement).

Reliability of the Survey Instrument(s)

The Cronbach Alpha test was performed to analyze the reliability and internal consistency of the instrument used against the data collected. The result shows a Cronbach Alpha value of 0.84 . Such result indicates a good level of internal consistency of the survey questionnaire and allows for further analysis without variable reduction.

\subsection{Population and Sample}

The population for this study consisted of teleworkers who work $100 \%$ remotely from home or a geographically convenience to resident to perform all official work duties. Teleworkers are employees who work for a company and do not commute to a brick-and-mortal workplace. The population selection was a random sample of 120 which was determined by using The $\mathrm{G}^{*}$ Power 3.1.9.2, a statistical power analysis and size calculating tool, was used to determine the sample size. [51] presented the GPower in the domain of correlation and regression analysis. According to [52], using power to calculate the sample is useful (p. 70). To calculate the sample size, the level of significance, power of the test, and effect size were specified. Demographic information collected included age, gender, education level, and number of years of service. The researchers deployed an electronically quantitative survey to collect data, and administered using QuestionPro, a web-based survey service.

In terms of the level of significance, 0.05 is the criterion for significance to ensure the cumulative Type I error remains below 0.05 [52]. The statistical power gives the investigator the ability to reject a null hypothesis when it is truly false [53], which is a Type II error [53] [54]. Using a power value of 0.80 indicates the population is established in conjunction to research outcomes indicate consistency with the population [52].

\subsection{Research Questions}

This study was an examination of the extent to which computer-mediated com- 
munications explained overall employee engagement among telecommuting knowledge workers in the US. The following research questions guided this study:

RQ: To what extent does competency in computer-mediated communication as defined by the factors of the CMC model (expressiveness, attentiveness, efficacy, knowledge, motivation) explain the variation in overall employee engagement of teleworkers?

$\mathrm{H}^{01}$ : Competency in computer-mediated communication (CMC) in Figure 1 significantly explains the variation in overall teleworker engagement.

\subsection{Data Analysis and Results}

The data analysis for this study proceeded first by analyzing the power obtained using a post hoc power analysis. This was followed by a Cronbach Alpha test [55] to ascertain the reliability of the survey instrument based on the data collected. A confirmatory factor analysis was then performed to confirm the factor structure of collected data and the use of the specified latent variables. This was followed by the validation of the assumptions of multiple regression and finally, a standard multiple regression model was created to test the previously stated hypothesis.

\section{Post Hoc Statistical Power Analysis}

To determine the appropriateness of the sample size used in this study, a post hoc power analysis was conducted using GPower 3.1.7, a statistical power analysis package suggested by [56]. The sample size of 134 was used for the power analysis along with 5 predictor variables as a baseline for the power equation. Cohen (1977) [57] recommends the following effect sizes: small $(f=0.02)$, medium $(\vec{f}=0.15)$, and large $(\vec{f}=0.35)$.

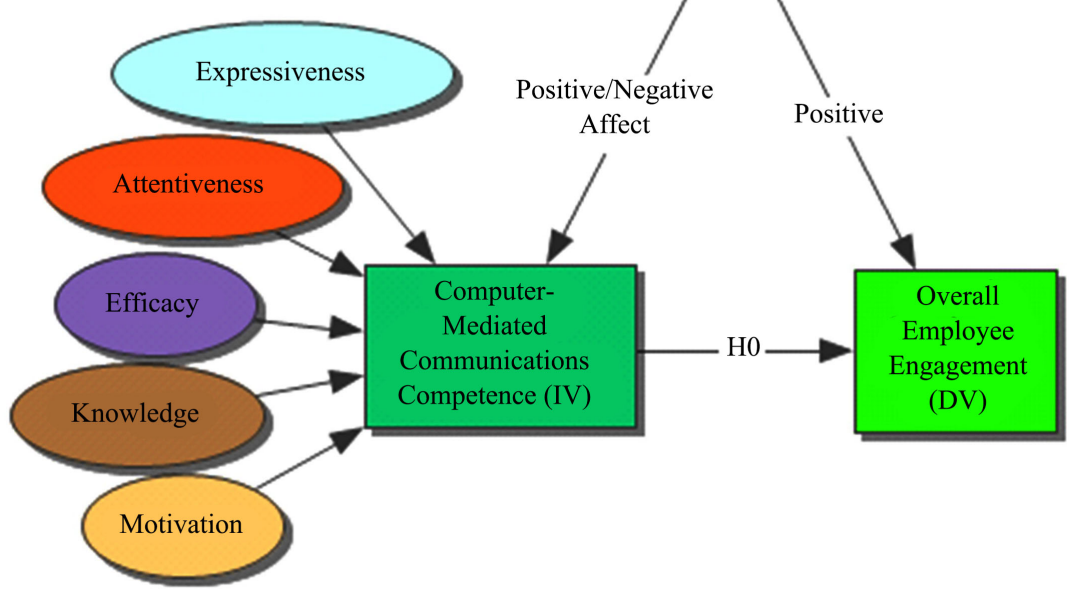

Figure 1. The relationship between independent variable, Computer-Mediated Communication $(\mathrm{CMC})$ competence and dependent variable Employee Engagement. 
For this study, all three effect sizes were used with an alpha level of $p<0.05$. The post hoc analysis revealed the statistical power for this study was 0.36 for the detection of a small effect, but the power exceeded 0.99 for detecting moderate to large effect sizes. [58] suggests adequate power is obtained for values above 0.80 . Hence, there was less than adequate statistical power at the small effect size level, but more than adequate power at the moderate to large effect size level.

\section{Confirmatory Factor Analysis}

A confirmatory factor analysis (CFA) was conducted to ascertain the structure of the latent variables relatively to that suggested by [44]. A representation of the expected structure is shown in Figure 2. The latent variables of the computer-mediated competency (CMC) scale used in this study are ATTENTIVENESS, EXPRESSIVENESS, MOTIVATION, EFFICACY, and KNOWLEDGE. They are represented in Figure 2 with their respective observed variables. The goal of this CFA is to test the null hypothesis suggesting that there is a relationship between the CMC factors and their underlying structure based on the data collected.

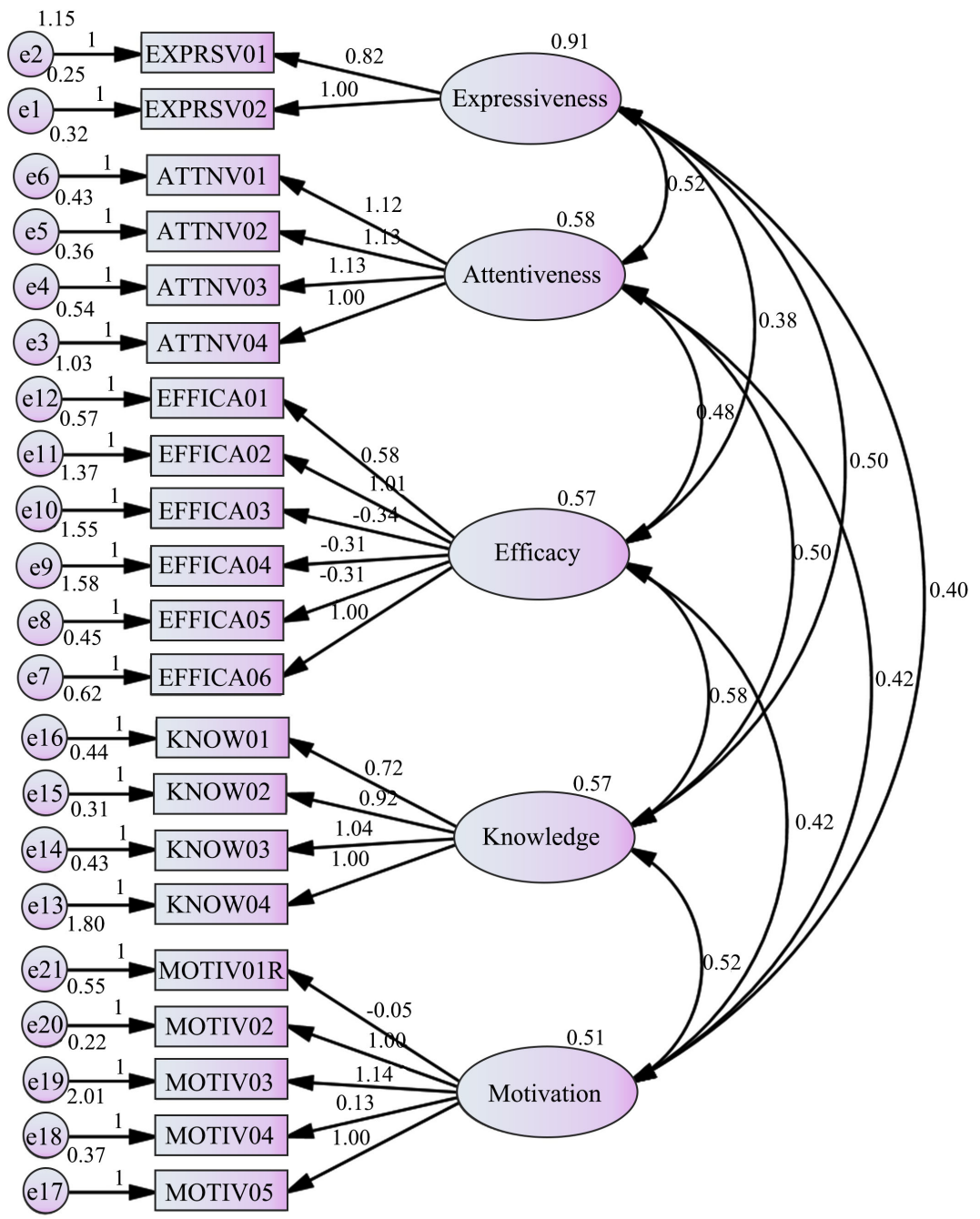

Figure 2. Hypothesized CFA model depicting the observed variable of CMC and their latent structure, with significant coefficients in standardized form. 
The assumptions of CFA were tested prior to proceeding with the analysis and interpretation of the results. Among them where the assumptions related to sampling size, missing data, outliers, normality of observed data, multicollinearity, and independence of residuals. Because the data had initially been purged of all incomplete responses, there was no missing value in the sample collected. Furthermore, the descriptive statistics of the $\mathrm{z}$-score of the observed variables showed that all $z$-scores were within the -3.29 to 3.29 range, thus confirming the absence of outliers on the observed variables.

The assumption of normality was assessed through the skewness and kurtosis values of each of the observed variables. All the observed variables had acceptable skewness and kurtosis values for normality as none of the standardized values was out of the range between -3.29 and 3.29 as suggested by [58].

The assumption of independence of results was conducted as part of the CFA. The test for multicollinearity showed signs of collinearity among various variables, which is expected for such a large number of observed variables. It was not deemed necessary to solve the multicollinearity issues because of the main aim in doing CFA: validating the structure of the latent variable.

Regarding the sample size, there were 134 respondents and 21 observed variables, representing a ratio of 6 to 1 . This value is less than the ratio of 8 to 1 suggested by [58] but is above the 5 to 1 ratio used by [59] in a study of computer-mediated communication competence applied to the online environment. Based on the preceding, this sample size was deemed acceptable for a CFA.

Confirmatory Factor Analysis. The confirmatory factor analysis was conducted using IBM Amos version 20. The graphical output of the analysis is represented in Figure 1. Additional text output shows model fitting indices $\left[\chi^{2} / \mathrm{df}=4.15 ; \mathrm{RMSEA}=0.15 ; \mathrm{GFI}=0.60\right.$; CFI $\left.=0.66\right]$. Besides the first value $\left(\chi^{2} / \mathrm{df}\right)$ holding an acceptable value, all other indices are border to their recommended good fit values. Such results are expected on small sample studies as discussed by [60]. Because the goal in doing CFA is not to optimize the model but to confirm the underlying structure, even though most indices did not fit well, the $\chi^{2} / \mathrm{df}$ was deemed acceptable to consider that the model fitted the data for this study. As such, the study could proceed with the consideration of the five latent variables of $\mathrm{CMC}$ as independent variables and implement a multiple regression analysis to validate the relationship between computer-mediated communication and employee engagement.

\section{Assumptions of the Multiple Regression}

In the analysis of the relationship between computer-mediated competency and employee engagement among the telecommuting knowledge workers, one dependent variable (DV) was identified and named ENGAGEMENT. This is a latent variable corresponding to the sum of scores of all the engagement questions in the survey. Five independent variables were also identified and used, namely ATTENTIVENESS, EXPRESSIVENESS, MOTIVATION, EFFICACY, and KNOWLEDGE. All five independent variables are latent variables deriving from the computer-mediated competency scale developed by [47] and published 
by [42]. All dependent and independent variables are the sums of their observed variables and measured at a scale measurement level in SPSS.

After confirming the scale measurement level of all variables, the assumptions of multiple regression where tested. As discussed by [58], these assumptions include: 1 ) ratio of cases to independent variables; 2 ) absence of outliers among the IVs and the DV; 3) absence of multicollinearity and singularity; 4) normality, linearity, and homoscedasticity of residuals; 5) independence of errors; and 6) absence of outliers in the solution.

Ratio of cases to independent variables. There were 134 respondents in this study, along with 5 independent variables. Thus, the number of cases is well over the minimum of 109 required. Indeed, the minimum number of cases required for testing individual predictors in a standard multiple regression is $104+5=$ 109 as explained by [58], assuming a medium size relation between the IVs and the DV $(\alpha=0.05, \beta=0.20)$.

Univariate outliers and missing values. A descriptive statistic of the z-score of the latent variables showed that all except one z-scores were within the -3.29 to 3.29 range. Hence, one outlier was discovered in the data. Analysis of the case showed that the respondent simply selected the first option for all questions. The record was removed from the collection, bringing the cases for multiple regression to 133. All prior statistics were re-computed and confirmed to stay unchanged as the removal of one case out of 134 did not affect the overall statistics as reported with two decimals.

Multivariate outliers. The identification of multivariate outliers was conducted by computing the Mahalanobis distance for each case, then calculating the probability that a value from the chi-square distribution with 5 degrees of freedom would be less than the obtain Mahalanobis distance [58]. To achieve this, a new variable was computed in SPSS using the Equation (1) - Cdf.Chisq $\left(M A H \_1,5\right)$, which is equivalent to using the formula sig.Chisq $\left(M A H \_1,5\right)$, with 5 being the degrees of freedom or number of independent variables in this study. Any resulting variable less than 0.05 (the desired alpha level) would indicate a multivariate outlier in the solution. In the case of this study, no multivariate outlier was detected.

Normality, linearity, homoscedasticity, and independence of residuals. A scatter plot was created with the standardized residual values on the $y$-axis and the standardized predicted values on the $\mathrm{x}$-axis. The plot showed a rectangular pattern and no point representing the residuals on the plot was outside the -3 to 3 range, suggesting that the assumption of independence and homoscedasticity was met. Furthermore, the normal P-P plot of the standardized residuals showed that standardized residuals were normally distributed. The Durbin-Watson statistic showed a value of 2.17 confirming that residuals were not serially correlated from one observation to the next as explained by [58].

Multicollinearity and singularity. Collinearity diagnostics were calculated using SPSS. The output showed the highest variance inflation factor (VIF) at 3.24, well below the limit of 10 considered risky for collinearity. Also, the colli- 
nearity tolerances were all above 0.30 . Hence, none of the tolerances calculated as 1 - SMC (squared multiple correlations) approached zero. Furthermore, collinearity analysis using the analyze/bivariate function in SPSS showed no correlation above 0.7 among the independent variables. As a result, multicollinearity and singularity were not causes of concern in this study.

\section{Results}

A standard multiple regression was performed to assess the ability to predict the dependent variable ENGAGEMENT using the independent variables ATTENTIVENESS, EXPRESSIVENESS, MOTIVATION, EFFICACY, and KNOWLEDGE. The analysis was performed using the functions Analyze/Descr-iptive statistics/Explore and Analyze/Regression/Linear on IBM SPSS version 24. The results of the evaluation of assumptions of multiple regression led to the removal of one case identified as outlier. Further analyses were performed to ensure there was no violation of the assumptions of multicollinearity and singularity; normality, linearity, homoscedasticity, and independence of residuals.

A significant regression equation was initially found $F(5,127)=20.03, p<$ 0.001 , with an $\mathrm{R}^{2}$ of 0.44 . In this model, the $p$-value associated with EFFICACY $(p=0.22)$ and KNOWLEDGE $(p=0.93)$ were not significant $(p>0.05)$. Indeed, the corresponding $95 \%$ confidence interval for B included 0 in both cases, suggesting that the variables could as well be zero. In other words, these two variables did not significantly contribute in predicting the independent variable. For that reason, both variables were eliminated from the solution hence the standard regression analysis was re-run and a new model created as shown in Table 1.

The final model $F(3,129)=32.96, p<0.001$ (see Table 1 ) has an $\mathrm{R}^{2}$ of 0.43 (see Table 2). Because the $\mathrm{p}$-value of each of the three variables used was significant $(p<0.05)$, the null hypothesis was rejected, suggesting there is enough evidence that ATTENTIVENESS, EXPRESSIVENESS, and MOTIVATION contribute in determining employee engagement among telecommuting knowledge workers. Indeed, the adjusted $\mathrm{R}^{2}$ value of 0.43 indicates that 43 percent of variability in employee engagement among telecommuting knowledge workers can be explained using variables ATTENTIVENESS, EXPRESSIVENESS, and MOTIVATION.

Table 1. Analysis of VARIANCE for the final model.

\begin{tabular}{ccccccc}
\hline \multicolumn{7}{c}{ ANOVA $^{\mathrm{a}}$} \\
\hline & Model & Sum of Squares & df & Mean Square & F & Sig. \\
\hline \multirow{3}{*}{1} & Regression & 9014.844 & 3 & 3004.948 & 32.960 & $0.000^{\mathrm{b}}$ \\
& Residual & 11760.945 & 129 & 91.170 & & \\
& Total & 20775.789 & 132 & & &
\end{tabular}

Note. a. Dependent Variable: ENGAGEMENT, b. Predictors: (Constant), MOTIVATION, EXPRESSIVENESS, ATTENTIVENESS. 
Table 2. Multiple regression model.

\begin{tabular}{lccccccccc}
\hline \multicolumn{10}{c}{ Model Summary $^{\mathrm{b}}$} \\
\hline Model & $\mathrm{R}$ & R Square & $\begin{array}{l}\text { Adjusted } \\
\text { R Square }\end{array}$ & $\begin{array}{l}\text { Std. Error of } \\
\text { the Estimate }\end{array}$ & $\begin{array}{c}\text { R Square } \\
\text { Change }\end{array}$ & F Change & df1 & df2 & $\begin{array}{c}\text { Sig. F } \\
\text { Change }\end{array}$ \\
\hline 1 & $0.659^{\mathrm{a}}$ & 0.434 & 0.421 & 9.548 & 0.434 & 32.960 & 3 & 129 & 0.000 \\
\hline $\begin{array}{l}\text { Note. a. Predictors: (Constant), MOTIVATION, EXPRESSIVENESS, ATTENTIVENESS, b. Dependent } \\
\text { Variable: ENGAGEMENT. }\end{array}$
\end{tabular}

The standardized coefficients in Table 3 show the most significant predictor of engagement to be ATTENTIVENESS $(B=0.36)$, followed by EXPRESSIVENESS $(B=0.30)$, then MOTIVATION $(B=0.16)$. The final multiple regression model is represented as follows:

ENGAGEMENT $=(1.31 \times$ ATTENTIVENESS $)+(1.82 \times$ EXPRESSIVENESS $)$ $+(0.56 \times$ MOTIVATION $)-0.87$

\section{Discussion}

This study used an explanatory quantitative, non-experimental research design. This research investigated the relationship between computer-mediated communication as defined by the factors of the CMC model (expressiveness, attentiveness, efficacy, knowledge, motivation) to overall employee engagement of telecommuting knowledge workers. This research provided significant results that indicate critical factors of engagement among telecommuting knowledge workers.

The results supported the hypotheses and suggested there was enough evidence that ATTENTIVENESS, EXPRESSIVENESS, and MOTIVATION contributed in determining employee engagement among telecommuting knowledge workers although Efficacy and Knowledge did not significantly contribute in predicting engagement. In fact, the data from Table 3 reveal the most significant predictor of engagement to be ATTENTIVENESS $(B=0.36)$, followed by EXPRESSIVENESS $(B=0.30)$, then MOTIVATION $(B=0.16)$. The final multiple regression model illustrated Engagement equals Attentiveness + Expressiveness + Motivation.

ENGAGEMENT $=(1.31 \times$ ATTENTIVENESS $)+(1.82 \times$ EXPRESSIVENESS $)$ $+(0.56 \times$ MOTIVATION $)-0.87$

Consistent with literature, Alarcon and Lyons (2011) described employee engagement as a multi-faceted concept that builds on positive emotions related to the level of engagement. Further, [35] argued that characteristics of work-life are strongly correlated with employee engagement; consequently, a sense of purpose and involvement must be the strongest driver for employee engagement. For these reasons, telework can be a positive alternative work method for employee engagement in an organization. Therefore, factors of the CMC model (attentiveness, expressiveness and motivation) are strongly correlated to telework because the characteristics of work-life are strongly correlated to employee engagement, and; Engagement $=$ Attentiveness + Expressiveness + Motivation . 
Table 3. Coefficients of the regression model.

\begin{tabular}{|c|c|c|c|c|c|c|c|c|c|c|}
\hline \multicolumn{11}{|c|}{ Coefficients $^{\mathrm{a}}$} \\
\hline & \multirow{2}{*}{ Model } & \multicolumn{2}{|c|}{$\begin{array}{l}\text { Unstandardized } \\
\text { Coefficients }\end{array}$} & \multirow{2}{*}{$\begin{array}{c}\begin{array}{c}\text { Standardized } \\
\text { Coefficients }\end{array} \\
\text { Beta }\end{array}$} & \multirow{2}{*}{$\mathrm{t}$} & \multirow{2}{*}{ Sig. } & \multicolumn{2}{|c|}{$\begin{array}{l}95.0 \% \text { Confidence } \\
\text { Interval for } B\end{array}$} & \multicolumn{2}{|c|}{$\begin{array}{l}\text { Collinearity } \\
\text { Statistics }\end{array}$} \\
\hline & & $B$ & Std. Error & & & & $\begin{array}{l}\text { Lower } \\
\text { Bound }\end{array}$ & $\begin{array}{l}\text { Upper } \\
\text { Bound }\end{array}$ & Tolerance & VIF \\
\hline \multirow{4}{*}{1} & (Constant) & -0.869 & 4.911 & & -0.177 & 0.860 & -10.586 & 8.847 & & \\
\hline & EXPRESSIVENESS & 1.822 & 0.489 & 0.302 & 3.729 & 0.000 & 0.855 & 2.789 & 0.669 & 1.495 \\
\hline & ATTENTIVENESS & 1.312 & 0.328 & 0.363 & 3.996 & 0.000 & 0.663 & 1.962 & 0.532 & 1.879 \\
\hline & MOTIVATION & 0.557 & 0.267 & 0.159 & 2.086 & 0.039 & 0.029 & 1.085 & 0.757 & 1.322 \\
\hline
\end{tabular}

Note. a. Dépendent Variable: ENGAGEMENT.

\subsection{General Implications}

This study provides several key research contributions. First, the proposed model examined computer-mediated communication (CMC) competency and employee engagement can serve as a theoretical platform to investigate, validate, and advance an understanding of when organizations allow telework, in turn, the employees are motivated, attentive, expressive and engaged while working. Secondly, this research was consistent with the characteristics of reciprocity as independent exchanges outline in the social exchange theory (SET). Despite the distinct ways SET has been used, scholars concur the social and economic exchange relations describes "a two-sided, mutually contingent, and mutually rewarding process involving 'transactions' or simply 'exchange” [21]. For instance, an organization may benefit from cost-efficient alternative of allowing employees to telework by reducing operation costs and office space. For the teleworker, benefits may include the flexibility of working from home while utilizing computer-mediated communications to exchange information and creating a work-life balance. Based on SET principles theoretically, relationships emerge into trusting, loyal, and mutual commitments over time considering the parties abide by certain "rules" of exchange [12]. The interdependence outcomes are established on a combination of parties' efforts which demonstrates something must be given for something in return [12]. Since interdependence involves a direct and negotiated agreement, for this reason, it is considered a defined characteristic of social exchange [59]. Moreover, the same interdependence characteristic of social exchange aligns with telework, a negotiated agreement between an employer and employee permitting flexible work arrangements from an approved location for an employee to perform work duties (Telework Enhancement Act of 2010) $)^{1}$.

\subsection{Organizational Implications}

The results of this research have important implications for organizations. The significance of this research to the Organization and Management field verified and filled the gap in existing literature by providing empirical evidence regard- 
ing the extent of competency in computer-mediated communication as defined by the factors of the CMC model to explain the variation in overall employee engagement of teleworkers.

The findings also have practical contributions to Human Resource Management. Several practitioners found employee engagement as a key factor to organizational success [34]. "Despite the contributions provided by many scholars, engaging employees is significant because the business cannot function without its employees" [17]. Further, studies concluded employee engagement is considered the employee's long-term commitment to the organization (Ali, Hussain, \& Azim, 2013) [61]. The more experienced, the more engaged the employee is engaged in their work.

\subsection{Limitation}

While this research supported the proposed theoretical framework, research question and made significant contributions to both academia and practice, there were limitations. The survey instruments used in this study were the UWES-9 [48] and CMC [42]. The instruments were selected with consideration to best reflect the theory that informed this research. SET provided the theoretical framework for this study. Although SET was deemed appropriate for this study for employee engagement and CMC, other tools or theories may explain or provide better measuring outcomes.

Second, this study was limited to quantitative data and causality should not be assigned to the relationships found in the findings. A third limitation was that a simple random sample of participants was recruited by a third-party provider, QuestionPro. Lastly, this study's population was general professional in the US.

Lastly, the results of this study only considered teleworkers in the United States. The opportunity to investigate other demographic variables will offer greater insight on factors that may influence engagement. These findings offer the opportunity for future studies to organizational culture, rewards, trust, and other workplace behaviors.

\subsection{Recommendations for Further Research}

The results of this study indicated that three of five competencies in computer-mediated communication as defined by the factors of the CMC model (expressiveness, attentiveness, motivation) had a statistically significant variance in overall employee engagement, and; efficacy and knowledge had no statistically significant variance in employee engagement. The results of the study revealed that employee engagement equals (expressiveness + attentiveness + motivation) implying that when these factors exist, then engagement exists. A recommendation for future research would be to assess the dimensions of engagement (absorption, dedication and vigor) against computer-mediated devices such as personal computers, tablets, or mobile devices in conjunction with types of communications required for work such as telephonically, video conferencing, in- 
stant messaging, email, collaboration platforms (Microsoft Teams or Slack). This could possibly provide more insight as to what facets interact more with the engagement dimensions in teleworkers. Additionally, a recommendation for further research would be to replicate the study using a different population, industry, or methodology, e.g. qualitative.

\section{Conclusions}

The premise of this study was to examine relationship of computer-mediated communication competency factors as defined by CMC model (expressiveness, attentiveness, efficacy, knowledge, motivation) to explain the variation in overall employee engagement of teleworkers. The research is grounded in existing employee engagement and computer-mediated communication literature. The overall research question proposed was: To what extent does competency in computer-mediated communication as defined by the factors of the CMC model (expressiveness, attentiveness, efficacy, knowledge, motivation) explain the variation in overall employee engagement of teleworkers? A multiple regression analysis indicated there was a statistically significant variance between computer-mediated communication competencies (Attentiveness, Expressiveness and Motivation) in determining employee engagement among telecommuting knowledge workers. Computer-mediated communication competencies (Efficacy and Knowledge) did not significantly contribute in predicting engagement. As organizations and Human Resources start to consider increasing employee engagement or creating teleworking opportunities, it may be worthwhile to take approaches to emotional analysis to better understand the motivation of its employees. There were three findings that were revealed from this current study:

1) Social exchange theory is a solid theoretical framework to study employee engagement and computer-mediated communication.

2) Employee engagement can be a predictor variable when examined against computer-mediated communication.

3) Employee engagement can statistically and significantly explain the relationship with computer-mediated communication competency factors (attentiveness, expressiveness and motivation) among knowledge teleworkers.

\section{Conflicts of Interest}

The authors declare no conflicts of interest regarding the publication of this paper.

\section{References}

[1] Sewell, G. and Taskin, L. (2015) Out of Sight, Out of Mind in a New world of Work? Autonomy, Control, and Spatiotemporal Scaling in Telework. Organization Studies, 36, 1507-1529. https://doi.org/10.1177/0170840615593587

[2] Jeske, D. and Axtell, C. (2014) e-Internships: Prevalence, Characteristics and Role of a Student Perspectives. Internet Research, 24, 457-473.

https://doi.org/10.1108/IntR-11-2012-0226 
[3] Hoang, A.T., Nickerson, R.C., Beckman, P. and Eng, J. (2008) Telecommuting and Corporate Culture: Implications for the Mobile Enterprise. Information Knowledge systems Management, 7, 77-97.

[4] Kaplan, S., Bradley-Geist, J.C., Ahmad, A., Anderson, A., Hargrove, A.K. and Lindsey, A. (2014) A Test of Two Positive Psychology Interventions to Increase Employee Well-Being. Journal of Business Psychology, 29, 367-380. https://doi.org/10.1007/s10869-013-9319-4

[5] Vega, R.P., Anderson, A.J. and Kaplan, S.A. (2015) A Within-Person Examination of the Effects of Telework. Journal of Business and Psychology, 30, 313-323. https://doi.org/10.1007/s10869-014-9359-4

[6] Coenen, M. and Kok, R. (2014) Workplace Flexibility and New Product Development Performance: The Role of Telework and Flexivle Work Schedules. European Management Journal, 32, 564-576. https://doi.org/10.1016/j.emj.2013.12.003

[7] Peters, P., Poutsma, E., van der Heijden, B.L., Bakker, B.B. and Thomas, B. (2014) Enjoying New Ways to Work: An HRM-Process Approach to Study Flow. Human Resource Management, 53, 271-290. https://doi.org/10.1002/hrm.21588

[8] Bartel, C.A., Wrzesniewski, A. and Wiesenfeld, B. (2012) Knowing Where You Stand: Physical Isolation, Perceived Respect and Organizational Identification among Virtual Employees. Organization Science, 23, 743-757.

https://doi.org/10.1287/orsc.1110.0661

[9] Kossek, E., Thompson, R.J. and Lautsch, B.A. (2015) Balanced Workplace Flexibility: Avoiding the Traps. California Management Review, 57, 5-25.

https://doi.org/10.1525/cmr.2015.57.4.5

[10] Pham, H. (2016) An Empirical Research on the Relationship between Leadership Behavior and Employee Engagement within Virtual-Working Environment at Technology Enterprises in Vietnam. 1-20. https://doi.org/10.2139/ssrn.2838542

[11] Suh, A. and Lee, J. (2017) Understanding Teleworkers' Technostress and Its Influence on Job Satisfaction. Internet Research, 27, 140-159.

https://doi.org/10.1108/IntR-06-2015-0181

[12] Cropanzano, R. and Mitchell, M.S. (2005) Social Exchange Theory: An Interdisciplinary Review. Journal of Management, 31, 874-900.

https://doi.org/10.1177/0149206305279602

[13] Blau, P.M. (1964) Exchange and Power in Social Life. John Wiley, New York.

[14] Gouldner, A.W. (1960) The Norm of Reciprocity: A Preliminary Statement. American Sociological Review, 25, 161-178. https://doi.org/10.2307/2092623

[15] Homans, G.C. (1958) Social Behavior as Exchange. American Journal of Sociology, 63, 597-606. https://doi.org/10.1086/222355

[16] Slack, R.E., Corlett, S. and Morris, R. (2015) Exploring Employee Engagement with (Corporate) Social Responsibility: A Social Exchange Perspective on Organizational Participation. Journal of Business Ethics, 127, 537. https://doi.org/10.1007/s10551-014-2057-3

[17] Tate, T.D. (2015) Performance Management and Employee Engagement in Small Businesses: A Correlation Analysis. Doctoral Dissertation. https://search.proquest.com/docview/1810428486? accountid=36783

[18] Aryee, S., Budhwar, P.S. and Chen, Z.X. (2002) Trust a Mediator of the Relationship between Organizational Justice and Work Outcomes: Test of a Social Exchange Model. Journal of Organizational Behavior, 23, 267-285.

https://doi.org/10.1002/job.138 
[19] Deckop, J.R., Cirka, C.C. and Andersson, L.M. (2003) Doing unto Others: The Reciprocity of Helping Behavior in Organizations. Journal of Business Ethics, 47, 101-113. https://doi.org/10.1023/A:1026060419167

[20] Ryan, J.J. (2001) Moral Reasoning as a Determinant of Organizational Citizenship Behaviors: A Study in the Public Accounting Profession. Journal of Business Ethics, 33, 233-244. https://doi.org/10.1023/A:1017584021475

[21] Emerson, R.M. (1976) Social Exchange Theory. Annual Review of Sociology, 2, 335-362. https://doi.org/10.1146/annurev.so.02.080176.002003

[22] Shuck, B., Twyford, D., Reio, T.G. and Shuck, A. (2014) Human Resource Development Practices and Employee Engagement: Examining the Connection with Employee Turnover Intentions. Human Resource Development Quarterly, 25, 239-270. https://doi.org/10.1002/hrdq. 21190

[23] Rosen, C.C., Harris, K.J. and Kacmar, K.M. (2011) LMX, Context Perceptions and Performance: An Uncertainty Management Perspective. Journal of Management, 37, 819-838. https://doi.org/10.1177/0149206310365727

[24] Michel, J.W. and Tews, M.J. (2016) Does Leader-Member Exchange Accentuate the Relationship between Leader Behaviors and Organizational Citizenship Behaviors? Journal of Leadership and Organizational Studies, 23, 13-26. https://doi.org/10.1177/1548051815606429

[25] Meyer, J.P. (2013) The Science-Practice Gap and Employee Engagement: It's a Matter of Principle. Canadian Psychology, 54, 235-245. https://www.cpa.ca https://doi.org/10.1037/a0034521

[26] Shore, L.M., Tetrick, L.E., Lynch, P. and Barksdale, K. (2006) Social and Economic Exchange: construct Development and Validation. Journal of Applied Social Psychology, 36, 837-867. https://doi.org/10.1111/j.0021-9029.2006.00046.x

[27] Andrew, O.C. and Sofian, S. (2012) Individual Factors and Work Outcomes of Employee Engagement. Procedia-Social and Behavioral Sciences, 40, 498-508. https://doi.org/10.1016/j.sbspro.2012.03.222

[28] Agarwal, U.A. (2014). Examining the Impact of Social Exchange Relationships on Innovative Work Behaviour: Role of Work Engagement. Team Performance Management, 20, 102-120. https://doi.org/10.1108/TPM-01-2013-0004

[29] Jose, G. and Mampilly, S.R. (2012) Satisfaction with HR Practices and Employee Engagement: A Social Exchange Perspective. Journal of Economics and Behavioral Studies, 4, 423-430.

[30] Hertlein, K.M. and Ancheta, K. (2014) Advantages and Disadvantages of Technology in Relationships: Findings from an Open-Ended Survey. The Qualitative Report, 19, 1-11. http://nsuworks.nova.edu/tqr/vol19/iss11/2

[31] Fernandez, P.C. and Rajan, A.P. (2015) Is It Important to Have Pride and a Sense of Belonging to the Organization One Works in? International Journal of Management Research and Review, 5, 629-635.

http://search.proquest.com.library.capella.edu/docview/1716947009?accountid=27965

[32] Gerst, R. (2013) Understanding Employee Engagement and Trust: The New Math of Engagement Surveys. The Journal for Quality and Participation, 35, 32-36.

[33] Burns, C. (2018) IT Employee Engagement and Job Satisfaction: An Explanatory Multiple Regression Analysis. Order No. 10845425, ProQuest Dissertations and Theses Global. https://search.proquest.com/docview/2111273750? accountid=36783

[34] Albrecht, S.L. (2012) The Influence of Job, Team and Organizational Level Resources on Employee Well-Being, Engagement, Commitment and Extra-Role Per- 
formance. International Journal of Manpower, 33, 840-853. https://doi.org/10.1108/01437721211268357

[35] Simon, S.S. (2011) The Essentials of Employee Engagement in Organizations. Journal of Contemporary Research in Management, 6, 63-72.

[36] Alarcon, G.M. and Lyons, J.B. (2011) The Relationship of Engagement and Job Satisfaction in Working Samples. The Journal of Psychology, 145, 463-480. https://doi.org/10.1080/00223980.2011.584083

[37] Bledow, R., Schmitt, A., Frese, M. and Kühnel, J. (2011) The Affective Shift Model of Work Engagement. The Journal of Applied Psychology, 96, 1246-1257. https://doi.org/10.1037/a0024532

[38] Bakker, A.B. and Leiter, M.P. (2010) Work Engagement: A Handbook of Essential Theory and Research. Psychology Press, Hove. https://doi.org/10.4324/9780203853047

[39] Schaufeli, W.B., Salanova, M., Gonzalez-Roma, V. and Bakker, A.B. (2002) The Measurement of Engagement and Burnout: A Two Sample Confirmatory Factor Analytic Approach. Journal of Happiness Studies, 3, 71-92. https://doi.org/10.1023/A:1015630930326

[40] Tejpal, P. (2015) Enhancing the Job Satisfaction Level through Dimensions of Employee Engagement: An Empirical Study on Private Sector Bank Managers. Drishtikon: A Management Journal, 7, 1-19. https://doi.org/10.21863/drishtikon/2015.7.1.010

[41] Karanika-Murray, M., Duncan, N., Pontes, H.M. and Griffiths, M.D. (2015) Organizational Identification, Work Engagement and Job Satisfaction. Journal of Managerial Psychology, 30, 1019-1033. https://doi.org/10.1108/JMP-11-2013-0359

[42] Spitzberg, B.H. (2006) Preliminary Development of a Model and Measure of Computer-Mediated Communication (CMC) Competence. Journal of Computer-Mediated Communication, 11, 629-666. https://doi.org/10.1111/j.1083-6101.2006.00030.x

[43] Hall, S. (1973) Encoding and Decoding in the Television Discourse. Centre for Contemporary Cultural Studies, Birmingham.

[44] Lee, E. and Oh, S.Y. (2015) Computer-Mediated Communication. Communication, Oxford Bibliographies Online Datasets. https://doi.org/10.1093/obo/9780199756841-0160

[45] Thurlow, C., Lengel, L. and Tomic, L. (2012) Computer-Mediated Communication: Social Interaction and the Internet. Sage Publications, Thousand Oaks.

[46] Giddens, 1999)

[47] Spitzberg, B.H. and Cupach, W.R. (1984) Interpersonal Communication Competence. Sage Publications, Beverly Hills.

[48] Schaufeli, W.B., Bakker, A.B. and Salanova, M. (2006) The Measurement of Work Engagement with a Short Questionnaire: A Cross-National Study. Educational and Psychological Measurement, 66, 701-716. https://doi.org/10.1177/0013164405282471

[49] Schaufeli, W.B. and Bakker, A.B. (2004) Job Demands, Job Resources and Their Relationship with Burnout and Engagement: A Multi-Sample Study. Journal of Organizational Behavior, 25, 293-315. https://doi.org/10.1002/job.248

[50] Bubbas, G. (2006) Competence in Computer-Mediated Communication: An Evaluation and Potential Use of a Self-Assessment Measure. International Communication Association Conference, Dresden, 1-26.

[51] Faul, F., Erdfelder, E., Buchner, A. and Lang, A.G. (2009) Statistical Power Analyses 
Using G*Power 3.1: Test for Correlation and Regression Analyses. Behavior Research Methods, 41, 1149-1160. https://doi.org/10.3758/BRM.41.4.1149

[52] Field, A. (2013) Discovering Statistics Using IBM SPSS Statistics. 4th Edition, SAGE Publications, Inc., Thousand Oaks.

[53] Swanson, R.A. and Holton III, E.F. (2005) Research in Organizations: Foundations and Methods of Inquiry. Berrett-Koehler Publishers, Inc., San Francisco, CA.

[54] Vogt, W.P. (2007) Quantitative Research Methods for Professionals. Allyn and Bacon, Boston, MA.

[55] Cronbach, L.J. (1951) Coefficient Alpha and the Internal Structure of Tests. Psychometrika, 16, 297-334. https://doi.org/10.1007/BF02310555

[56] Faul, F., Erdfelder, E., Lang, A.-G. and Buchner, A. (2007) G*Power 3: A Flexible Statistical Power Analysis Program for the Social, Behavioral and Biomedical Sciences. Behavior Research Methods, 39, 175-191. https://doi.org/10.3758/BF03193146

[57] Cohen, J. (1992) A Power Primer. Psychological Bulletin, 112, 155-159. https://doi.org/10.1037/0033-2909.112.1.155

[58] Tabachnick, B.G. and Fidell, L.S. (2013) Using Multivariate Statistics. 6th Edition, Pearson, Upper Saddle River.

[59] Bubaš, G., Radošević, D. and Hutinski, Ž. (2003) Assessment of Computer Mediated Communication Competence: Theory and Application in an Online Environment. Journal of Information and Organizational Sciences, 27, 55-67.

[60] Lartey, F.M., Hargiss, K. and Howard, C. (2015) Antecedents of Customer Satisfaction Affecting Broadband Loyalty: An Implementation of SERVQUAL and NPS. International Journal of Strategic Information Technology and Applications, 6, 26-41. https://doi.org/10.4018/IJSITA.2015010103

[61] Ali, M.A., Hussain, A. and Azim, A. (2013) Organizational Investment in Social Capital (OISC) and Employee Job Performance: Moderation by Employee Job Engagement. International Review of Management and Business Research, 2, 250-257. http://irmbrjournal.com/papers/1367573449.pdf 